\title{
Real Time Based Fuzzy Logic Distance Protection
}

\author{
Dr. Maamoon F. Al-Kababji, PhD., \\ Electrical Engineering Department, University of Mosul, Email: Alkababji@yahoo.com
}

\begin{abstract}
This paper presents a new approach to real-time fault detection in power transmission systems using Fuzzy Logic (FL) based transmission line distance protection module. The proposed module uses samples of voltage and current signals to calculate line impedance, which used to construct an input-output data.

Simulation studies are preformed and influence of changing system parameters such as fault resistance and fault location. Details of the design procedure and the results of performance studies with the proposed relay are given.

Practical computer simulation program for monitoring the input and calculated values is built based on the Matlab 7.4- Real Time Simulink with National Instruments Data Acquisition System type (NI DAQ-6251). The results show that this approach can be used as an effective tool for high speed digital relaying, a correct detection is achieved in less than $10 \mathrm{~ms}$, results performance shows that the proposed algorithm is fast and accurate as compared with others used relays.
\end{abstract}

Keywords: Transmission line protection, Distance relay, Fuzzy logic, and MatlabSimulink.

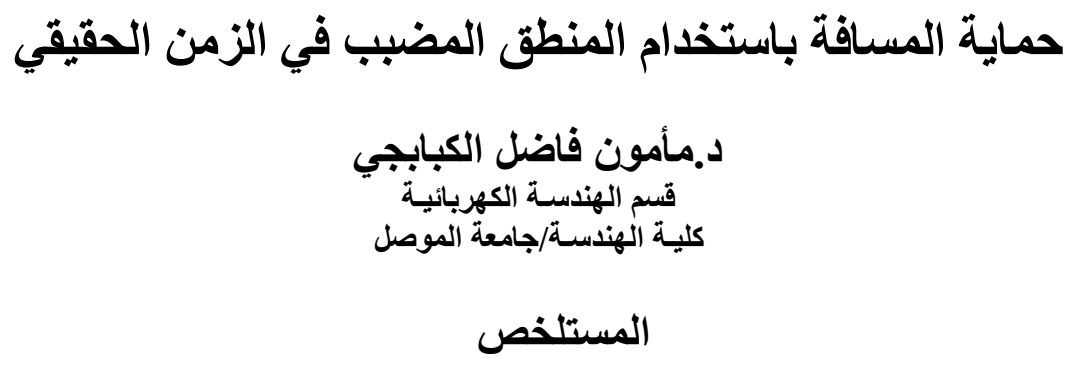

يقلم هذا البحث طريقة جديدة للكثف عند الخطأ بالزمن الحقيقي في نظم نقل الطاقة الكهربائية باستخدام

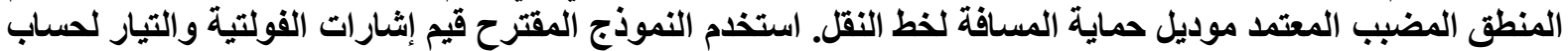

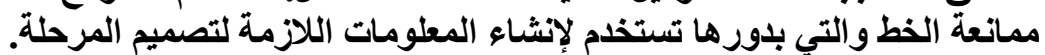
التحليل باستخدام الحاسبة اخذ لعدة حالات مثل تغير مقاومة العطل بالإضافة إلى موقعه. وأعطيت تفاصيل التصميم للمرحلة المقترحة.

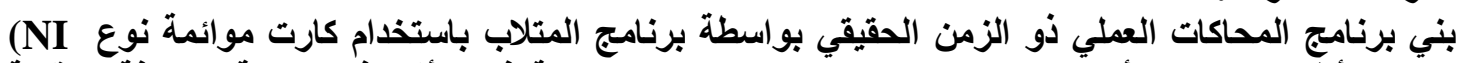

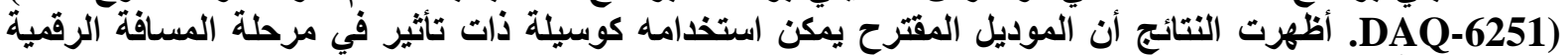

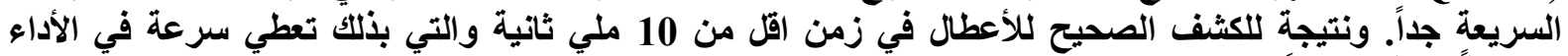

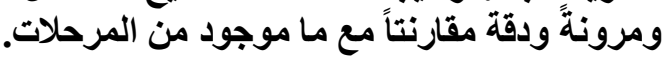




\section{Introduction}

Power transmission lines are the vital links that provide the essential continuity of the service from generating plants to customers. They are spread over wide regions and are exposed to various types of faults. Protection of transmission lines against exposed faults is one of the most challenging functions in power system protection. Transmission line distance protection systems have been widely applied in power system protection. By measuring voltage and current signals, distance relays respond to the impedance between the relay and the fault location.

It is known that distance relays, and in particular ground distance function measurements are affected by fault resistance. Fault resistance is an operational problem and is not a constant parameter in nature. It depends on various factors such as voltage level, tower footing resistance, resistivity of soil and environmental conditions. Fault resistance produces an error in the impedance measurement and thus could affect the accuracy of the relay severely. The relay may over-reach/under-reach, which can result in false tripping and error operation. Moreover, the relay measurements are affected by source impedances and system configuration changes. Adaptive protection relaying approaches have been proposed to consider these system changing variables [1].

Recently, many researchers have studied the application of fuzzy logic to overcome some of the problems above outlined [2]. The use of fuzzy logic in applications is very sparse due to its implicit knowledge representation. The key benefit of fuzzy logic is that its knowledge representation is explicit, using simple "IF-THEN" type of relations.

In this paper, the design integration of fuzzy logic system which construct membership functions depend on the practical input-output data set resulting in excellent and fast response of real time relay action.

\section{Distance protection}

Distance relays are responsible to distinguishing between different faults inside and/or outside of the protection zones. When setting distance protection, the widely accepted practice is to allow a setting margin of approximately $20 \%$ for the first protection zone. This is necessary to allow for measurement errors, relay inaccuracy and inherent errors in estimating line impedance, due to some fault such as fault resistance, presence of dc offset and remote in-feed. The first zone of the distance relay is therefore set to approximately $80 \%$ of the positive sequence impedance of the protected line. The remaining $20 \%$ of the line is covered by a time delayed second zone operation. When a line is protected by distance relays at both ends, faults in the mid $60 \%$ of the line will be cleared by both relays in zone 1 with the fastest relay operational speeds, e.g. about one cycle duration. On the other hand, faults in the two line-end regions (each 20\%) are covered by zone 2 from one end with the clearance time of typically 20 cycle duration which might be not fast enough for system stability or other reasons [3].

\section{Transmission Line Impedance:}

Positive sequence line impedances are generally estimated at the temperature of maximum load current in high temperature season and with complete transposition of the conductors along the line, without consideration of any resistance increase due to the conductor connection in every jumper point and sometimes without knowing the exact length of the line. The overhead lines are assumed to be long, straight conductors for calculating its reactance. It is true that the conductors actually sag from tower to tower not in identical shape. They may cause an error in impedance estimation even though their values are not so high. For the bundle conductors their impedance can be determined as a single conductor by 
reducing the several conductors per phase to a single equivalent conductor using geometric mean distance (GMD) and geometric mean radius (GMR). In this equivalent modeling there may be some numerical difference between the actual value and its equivalent also [4].

Even the resistance of the line is variable according to ambient temperature, magnitude of load current and situation of connecting point, but the reactance of the line remains constant all the time.

\subsection{Measuring by four terminal equations}

The impedance of the line can be measured by Ohm's Law; the line impedance is the voltage drop divided by line current. Basically equation (1) represents the relation of them.

$$
Z=\frac{E_{S}-E_{R}}{I_{e q}}
$$

where $\mathrm{Z}$ is a series impedance of the line, Es, $\mathrm{E}_{\mathrm{R}}$ are voltages at the sending end and at the receiving end respectively, and $\mathrm{I}_{\mathrm{eq}}$ is the equivalent current throughout all the line in terms of voltage drop. However it is not easy to find out $\mathrm{I}_{\mathrm{eq}}$ because currents at both ends are not the same due to the effect of charging current and leakage current along the line, which are represented by hyperbolic functions. The distributed-parameter circuit as shown in Figure (1) can be an equivalent of a transmission line in detail. In this circuit the sending end voltage $\mathrm{E}_{\mathrm{S}}$, and current $\mathrm{I}_{\mathrm{S}}$ can be represented by the four-terminal equations as given in equation (2).

$$
\left.\begin{array}{l}
E_{S}=A E_{R}+B I_{R} \\
I_{S}=C E_{R}+D I_{R}
\end{array}\right\}
$$

where:

$$
\begin{aligned}
& A=\cosh (\gamma), B=Z c \cdot \sinh (\gamma), C=\frac{1}{Z c} \cdot \sinh (\gamma l), D=\cosh (\gamma) \\
& (\gamma)=\sqrt{z y} \cdot l=\alpha+j \beta, Z c=\sqrt{z / y}, \text { and } \mathrm{z}, \mathrm{y} \text { is an impedance }(\Omega / \mathrm{km}) \\
& \text { and an admittance }(\mathrm{mho} / \mathrm{km}) \text { of the line, respectively. }
\end{aligned}
$$

If synchronized phasors $E_{S}, I_{S}$ and $E_{R}, I_{R}$ are measured more than twice in different load flow conditions; i.e. at off- peak and peak, and/or at different power factors $(\cos \square)$, then they will give more than two set of four-terminal equations. A,B,C,D parameters, therefore, could be calculated from those equations by matrix inversion or any iteration methods. It is well known that the parameter B represents merely a series impedance in the nominal equivalent $\mathrm{p}$ circuit for less than $200 \mathrm{~km}$ length line [4]. It means that if the line is short or medium length, the impedance of the line is almost same as or very close to parameter B so that $\mathrm{Z}=\mathrm{B}$ can be acceptable.

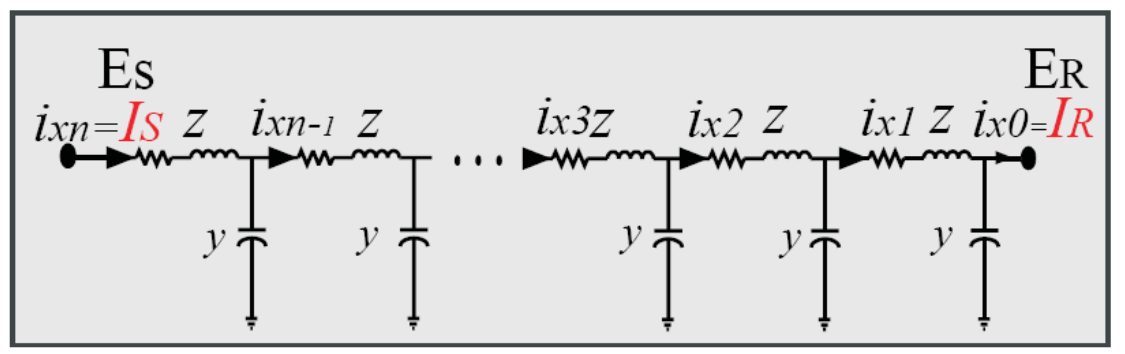

Figure (1), Equivalent circuit of transmission line. 


\section{Performance improvement:}

The proposed relay was tested with a large set of input values covering a wide range of different power system conditions. Figure (2) could be used to clarify the reason of equality of the calculated impedances. $Z_{R}$, the seen impedance by the relay located at the beginning of the transmission line, is demonstrated for two different cases where power angle $\mathrm{d}$ is positive and/or negative. The seen impedance at the relay location calculated by DFT algorithm is given by equation (3) [1].

$$
Z_{\mathrm{R}}=\frac{V_{\mathrm{a}}}{I_{\mathrm{a}}+K I_{0}}=Z_{1 \mathrm{f}}+\left(\frac{3 I_{0 \mathrm{f}}}{I_{\mathrm{a}}+K I_{0}}\right) R_{\mathrm{F}} \mathrm{e}^{j\left(I_{0 f} /\left(I_{a}+K I_{0}\right)\right)}
$$

where

$\mathrm{V}_{\mathrm{a}}$ is voltage of phase $\mathrm{A}$

$I_{a}$ is current of phase $A$

$\mathrm{I}_{0}$ is zero sequence component of the phase A current

$\mathrm{K}$ is zero sequence compensation factor

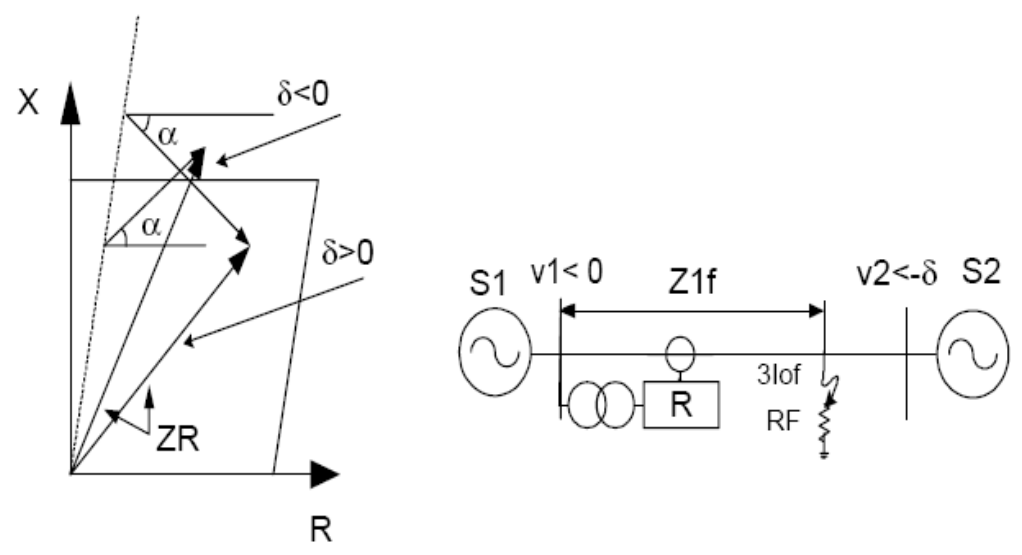

Figure (2). Impedance calculation by distance relay for different faults.

If the power angle is not equal to zero, fault resistance $\mathrm{R}_{\mathrm{F}}$ would include a resistive part as well as a reactive part. The reason for appearance of the fault resistance as a resistive part plus a reactive part at the relay location is that the fault current angles flowing towards the fault from sources $\mathrm{S} 1$ and $\mathrm{S} 2$ are not equal. As such $\mathrm{Z}_{\mathrm{R}}$ would include an inductive and/or capacitive component, depending on the direction of power flow and sign of the power angle. As a result, in some fault cases, an out of zone fault appears to be inside the zone boundary. In some other cases, an inside zone fault appears to be outside of the protection zone.

In order, to be able to discriminate between faults inside and outside of the protection zone in all forward and reverse power flow directions, it is suggested to add a new input to the fuzzy system. This way, different system fault points, which were mapped to a similar point, could be discriminated more effectively using the new decision space.

It would be a good idea to use the power angle as an input to the fuzzy logic. However, this angle could not be estimated easily and is not accessible at the relay location. So, a different parameter should be used as the network is input to represent the power angle effect indirectly. Referring to Figure (2), it could be shown that the alpha a angle could be calculated as: 


$$
\alpha=\operatorname{Arg}\left(\frac{I}{I_{\mathrm{a}}+k_{0} I}\right)=\operatorname{Arg} \frac{I}{I_{\alpha}+k_{0} I_{0}}+\theta
$$

The $(\alpha)$ angle depends on the system structure and location of the fault. For a homogenous power system, i.e. where angles of the source impedance and line impedance are equal, $(\alpha)$ would be constant. In real power systems, these angles are almost equal. Therefore, this angle could not be used to add a new dimension to the input space. Referring to equation (4) it seems that the zero sequence current $\mathrm{I}_{0}$ (or the neutral current $I_{n}$ ) measured at the relay location could be a good parameter indicating variations of the power angle.

In another word, the values of measured resistance and reactance lead directly to give the state of system if transmission line

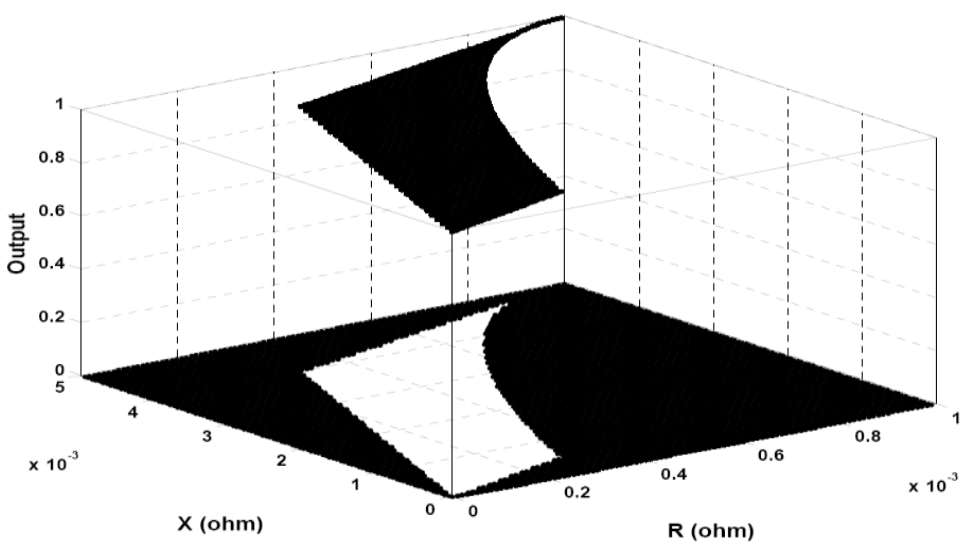

Figure (3) The three dimensions input-output characteristics of proposed relay parameters are given. Figure (3) shows the three dimensions input output characteristics of proposed distance intelligent relay, this relay design depending on the characteristic of tested transmission line with max length about $300 \mathrm{~km}$, where these characteristics have two level output one for trip signal (fault happened) and zero for normal system operation. These characteristics used for construct an input-output data set for fuzzy system.

\section{Fuzzy Systems in power system protection:}

The fuzzy signal processing and fuzzy reasoning techniques (belonging to the family of Artificial Intelligence) have gained remarkable attention for at least 15 years and numerous studies have been performed in world-leading research centers with regard to their application also for power system protection and control tasks. Fuzzy Logic systems (FL) are well suited for solving various decision-making problems, especially when the precise analytical model of the process/object to be tracked is not known or is very complicated (e.g. non-linear) [2]. Analysis of power system faults and other abnormal phenomena belongs to the family of tasks that can be quite well carried out with use of FL based decision modules or classifiers.

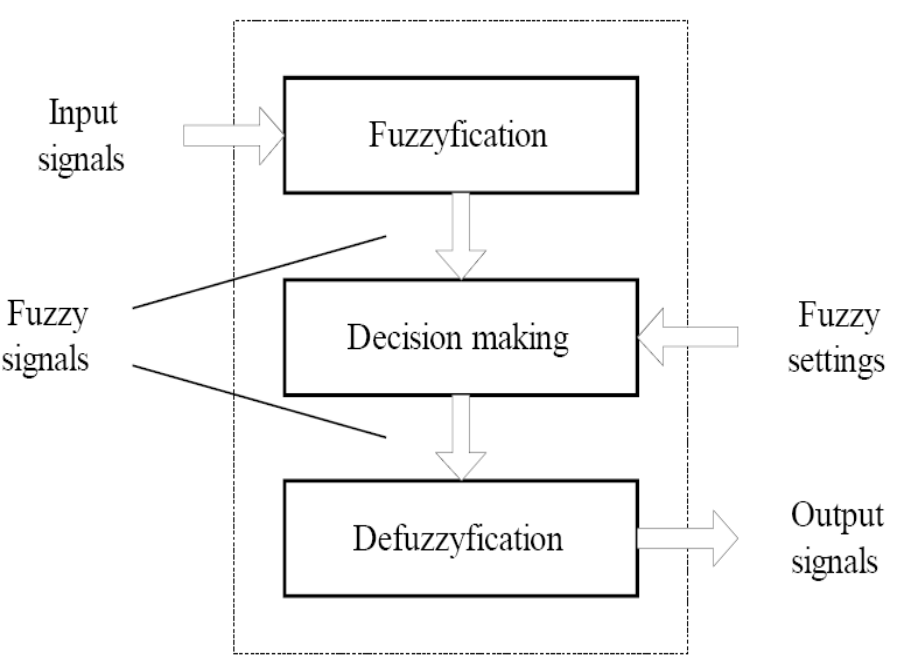

Figure (4), Basic structure of a fuzzy reasoning 
Fuzzy Inference Systems (FIS) employ the theory of fuzzy sets and fuzzy if-then rules to derive an output. Various types of FIS are often used either for fuzzy modeling or for fuzzy classification purposes. Typically a FIS scheme performs, as shown in Figure (4),its action in several steps including:

- fuzzyfication (comparing the input values with

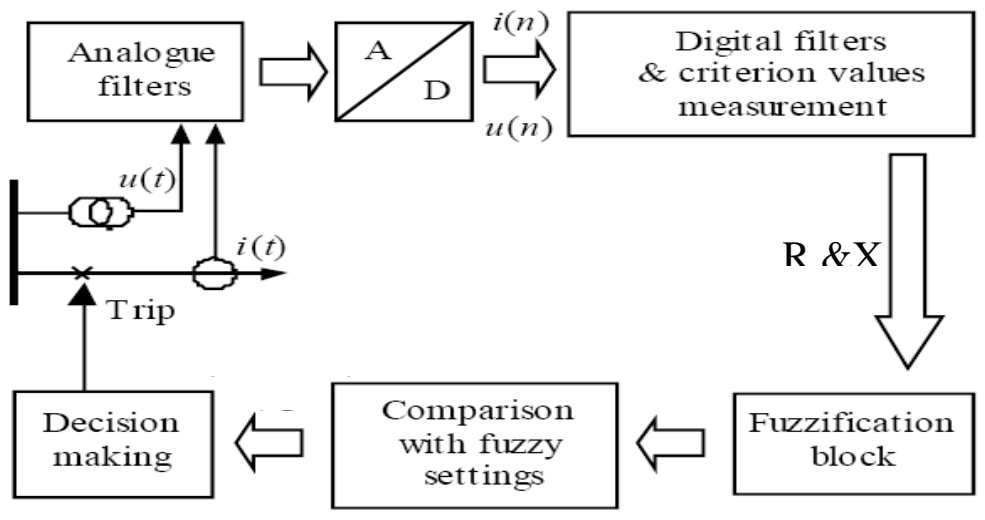

Figure (5) Block scheme of the FL-based distance protection. membership functions to obtain membership values of each linguistic term).

- fuzzy reasoning (firing the rules and generating their fuzzy or crisp consequents).

- defuzzyfication (aggregating rule consequents to produce a crisp output).

\section{Fuzzy Logic Based Distance protection Relay:}

In this paper a fuzzy approach to distance protection of power transmission line is studied. The protection solution developed, as shown in Figure (5), takes advantage of fuzzy signal processing and fuzzy comparison to issue trip decision, depending on training inputoutput data, shown in Figure (3).

The inference method, which is used in design the proposed relay, was TakagiSugeno's. The proposed relay scheme has been tested on a variety of processes as designed depending on training input-output data. The membership function (MF) of these fuzzy input sets, are as shown in Figure (6) and (7). In these Figure, VH represents Very High, VM Very Medium, and so on to VL Very Low. Fuzzy sets for crisp output membership function may be either one or zero.

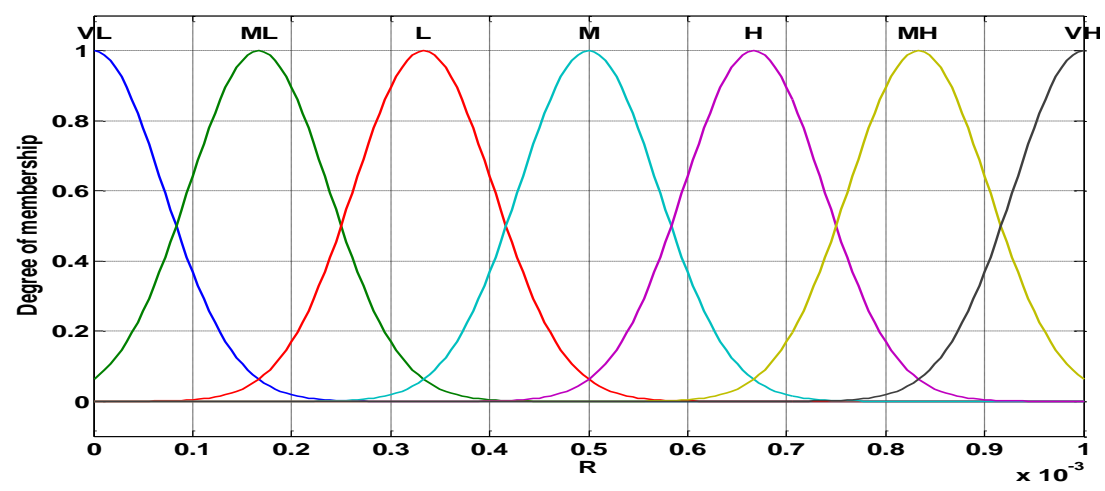

Figure (6) Fuzzv input membership function for line resistance 


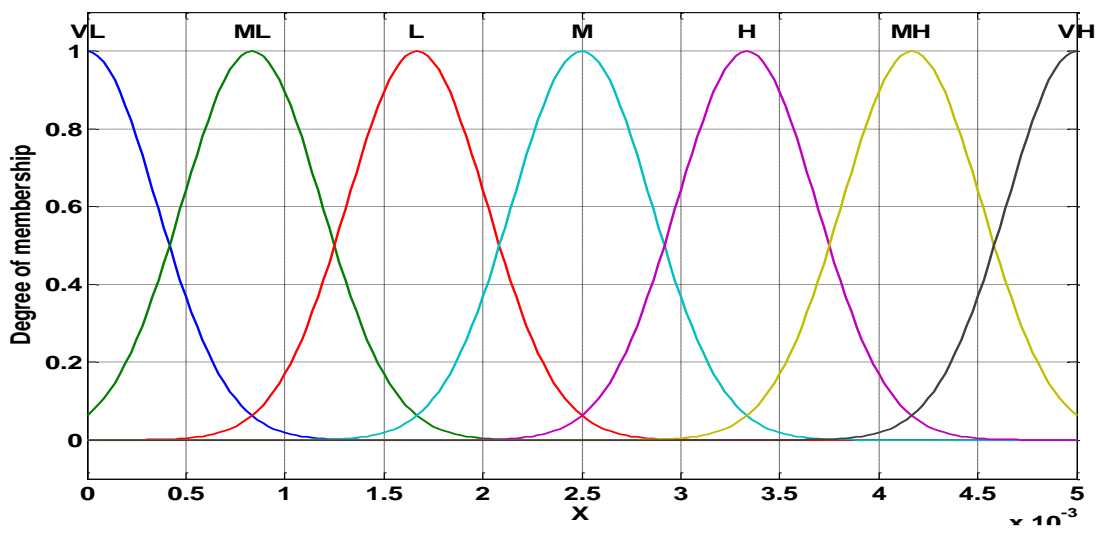

Figure (7) Fuzzy input membership function for line reactance (X)

The intelligent proposed relay as modeled in Matlab-Simulink is shown in Figure (8).which has two fuzzy variables resistance $(\mathrm{R})$ and reactance $(\mathrm{X})$ and seven linguistic variables for each, from very low to very high, as shown in Figure (6) and (7). Multi test results are shown in Figures $(9,10)$. The fuzzy logic based distance protection proposed relay attributes and all details are given in following summary:

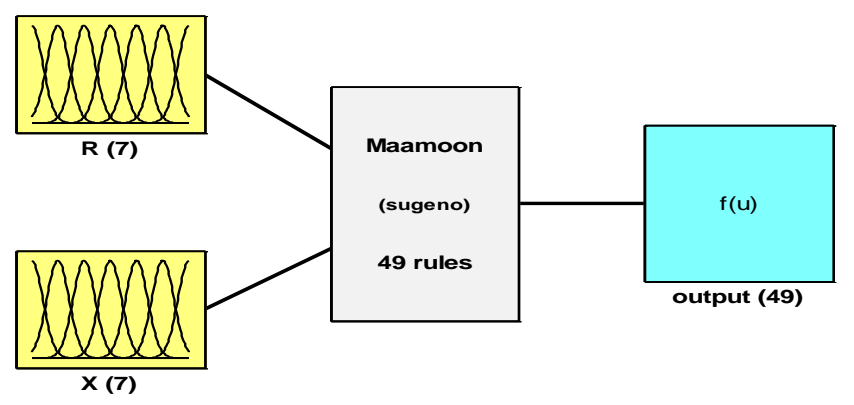

System Maamoon: 2 inputs, 1 outputs, 49 rules

Figure (8) Fuzzy Logic overall diagram

name: 'Maamoon'

type: 'sugeno'

andMethod: 'prod'

orMethod: 'max'

defuzzMethod:

'wtaver'

impMethod: 'prod' aggMethod: 'sum' input: [1x2 struct] output: [1x1 struct] rule: [1x49 struct]

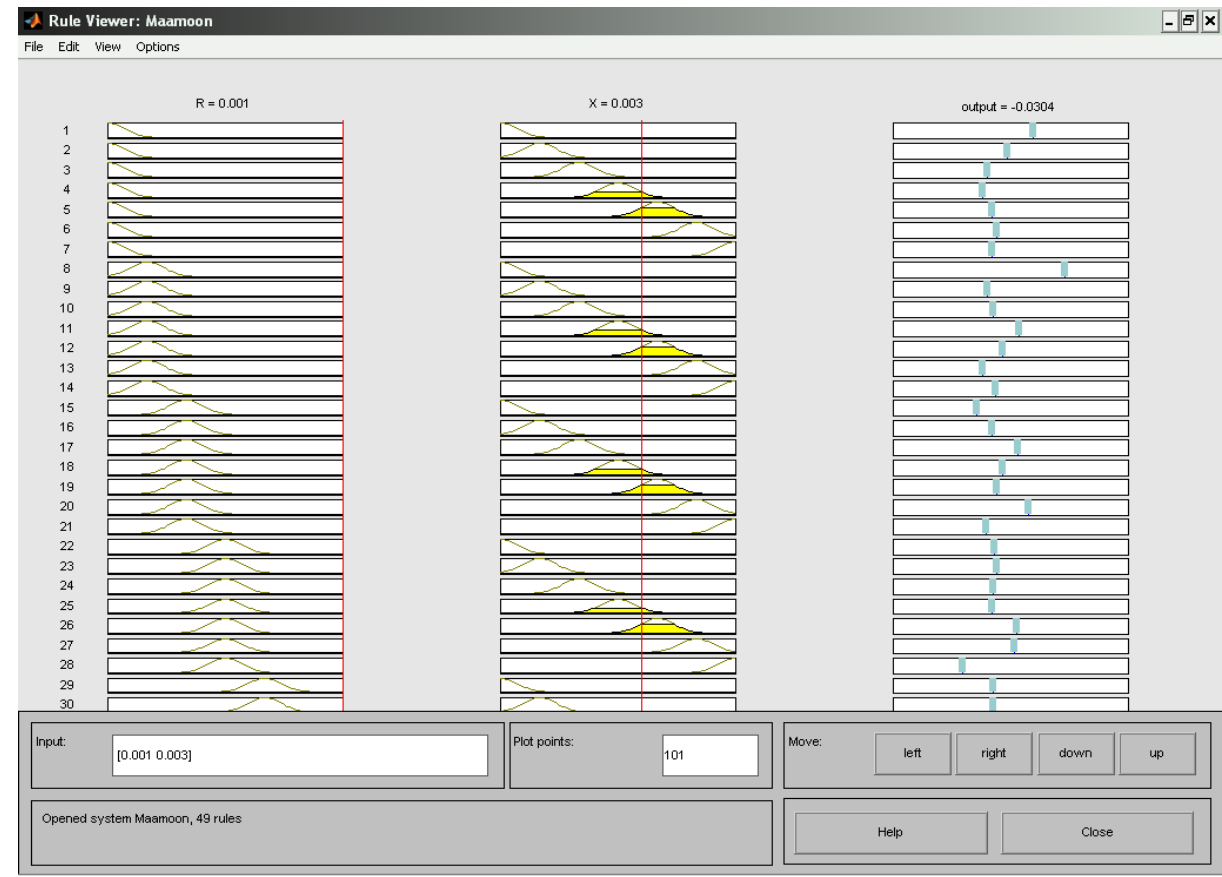

Figure (9) Test results of membership function \& Sugeno corresponding response. 

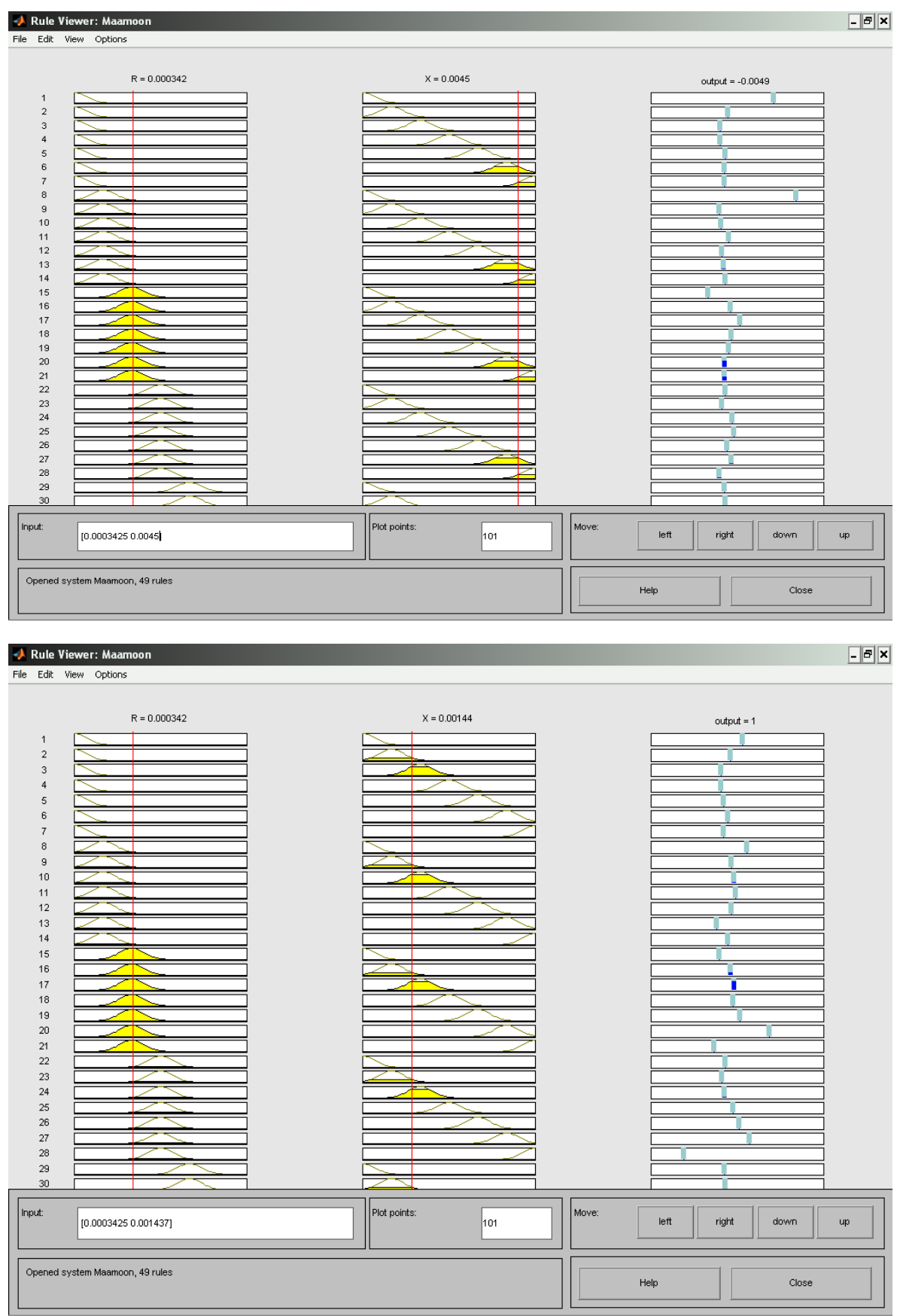

Figure (10) Test results of membership function \& Sugeno corresponding response.

\section{7- Practical Result}

The theoretical results were tested on a practical simulation $300 \mathrm{~km}$. transmission line length in the lab Figure (11), the rating value of all parameters are given in appendix, after taking the practical information data from transmission line as voltage and current signals, using National Instruments Data Acquisition System type (NI DAQ-6251), compute the resistance and reactance, then fed to it fuzzy block to take the decision, and send it to circuit breaker in case of fault as shown in Figure (12). 


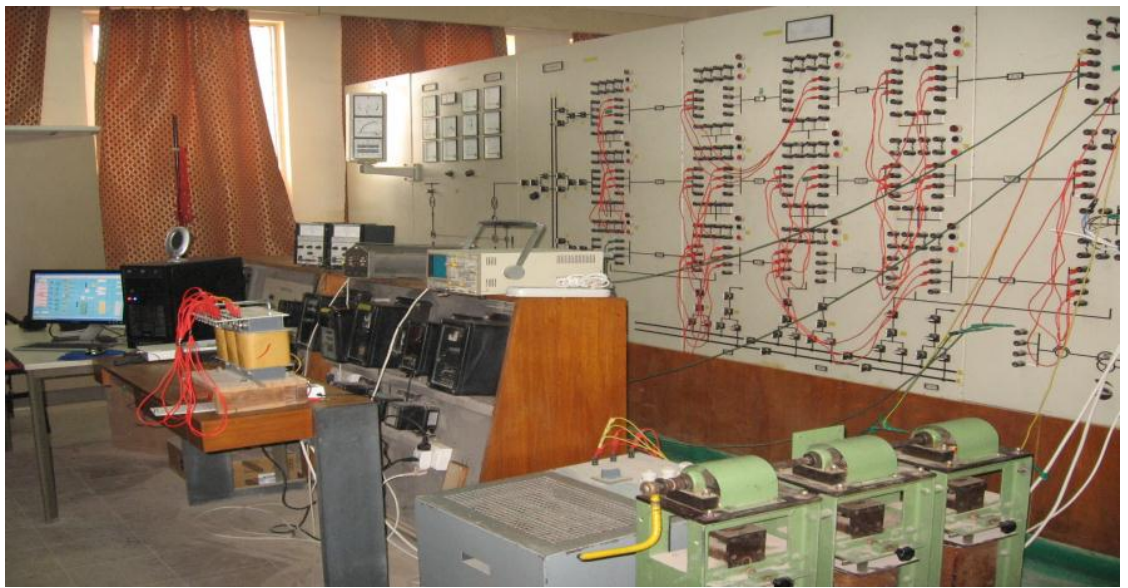

Figure 11. Practical simulation transmission system

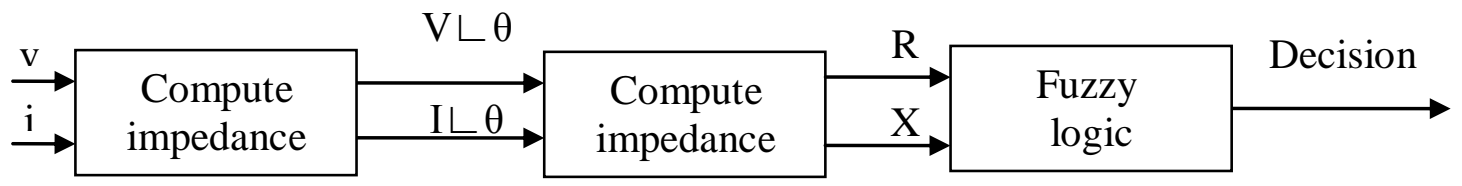

Figure (12). testing

A test for two cases, phase (a) to ground fault and phase (a and b) to ground fault at fault location 100km. Figure (13) and figure (16) show voltage and current signals for the two kind of faults. The results are shown below, Figure $(14,15)$ show the case of fault (a) to ground without $(\mathrm{Rf})$ and with $(\mathrm{Rf})$ equal $(0.0001 \mathrm{ohm})$ receptivity, figure $(17,18)$ show the case of fault (a) and (b) to ground without (Rf) and with (Rf) equal $(0.0001 \mathrm{ohm})$ receptivity, another case for phase (a) to ground fault at $200 \mathrm{~km}$ fault location are tested, Figure (19) show voltage and current signals, Figure $(20,21)$ show the case of fault (a) to ground without (Rf) and with (Rf) equal $(0.0001 \mathrm{ohm})$ receptivity .It can be seen that the relay had detected the faults.

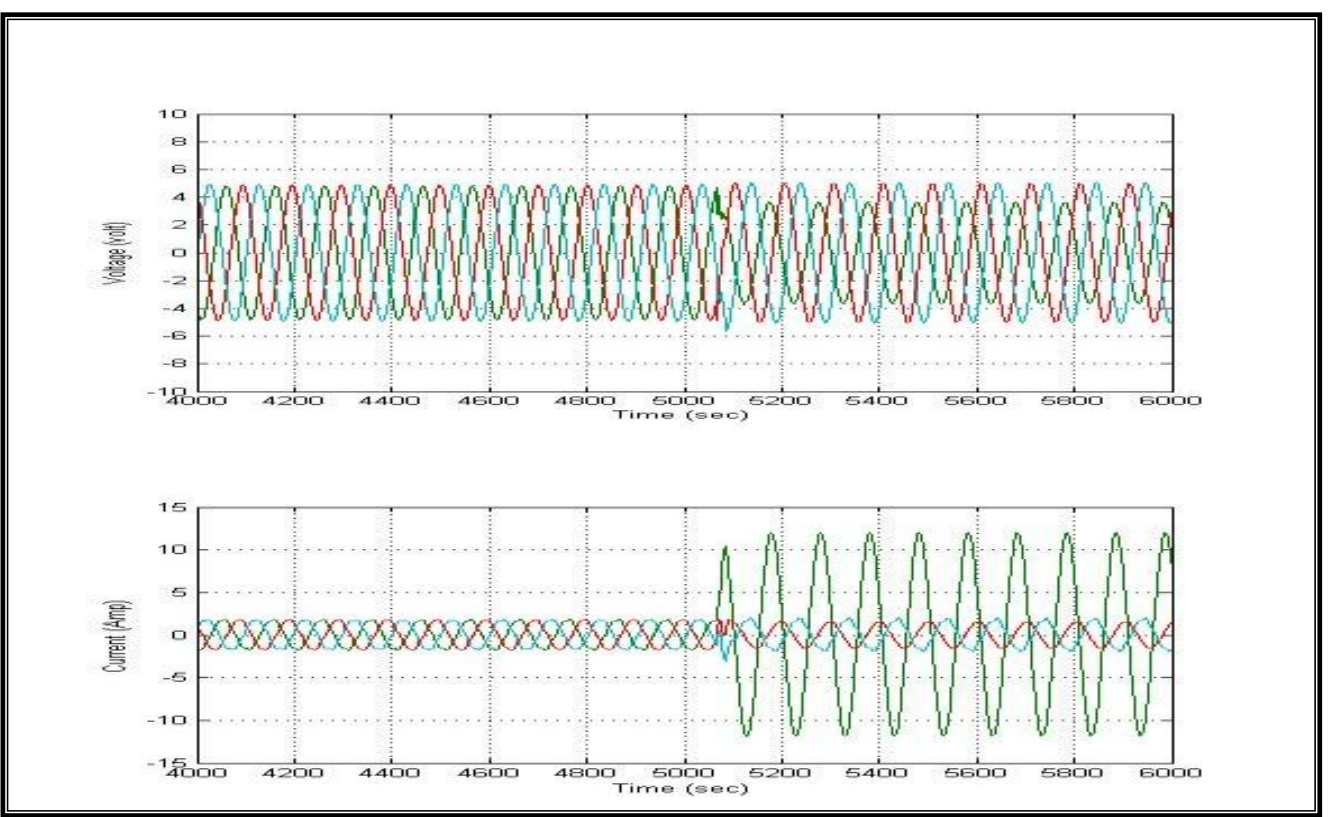

Figure (13) voltage and current signals for phase a to ground fault at $100 \mathrm{~km}$ 


$\begin{array}{llll}\text { Al-Rafidain Engineering } & \text { Vol.20 } & \text { No. 3 } & \text { June } 2012\end{array}$

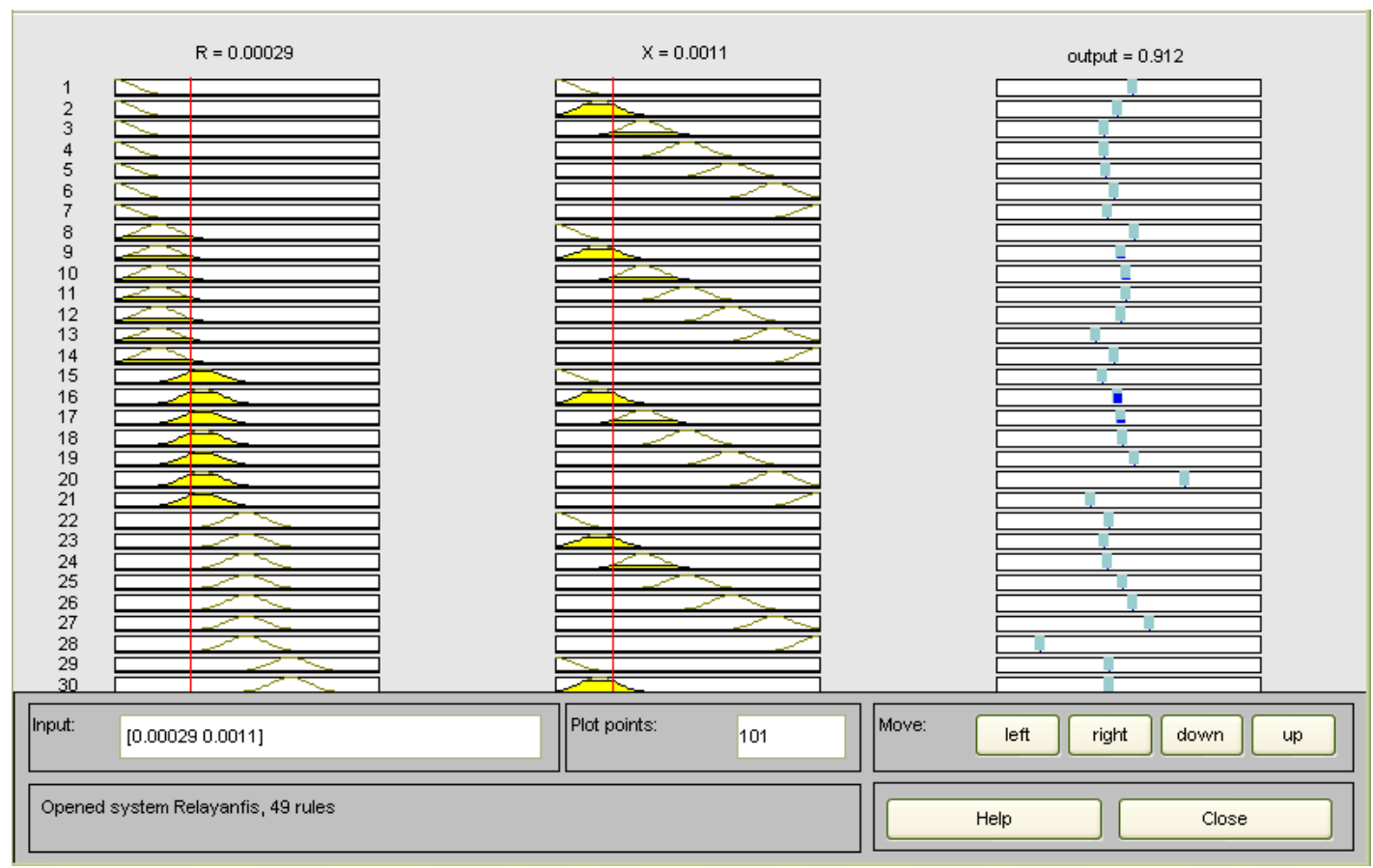

Figure (14) Test results of membership function \& Sugeno corresponding response.

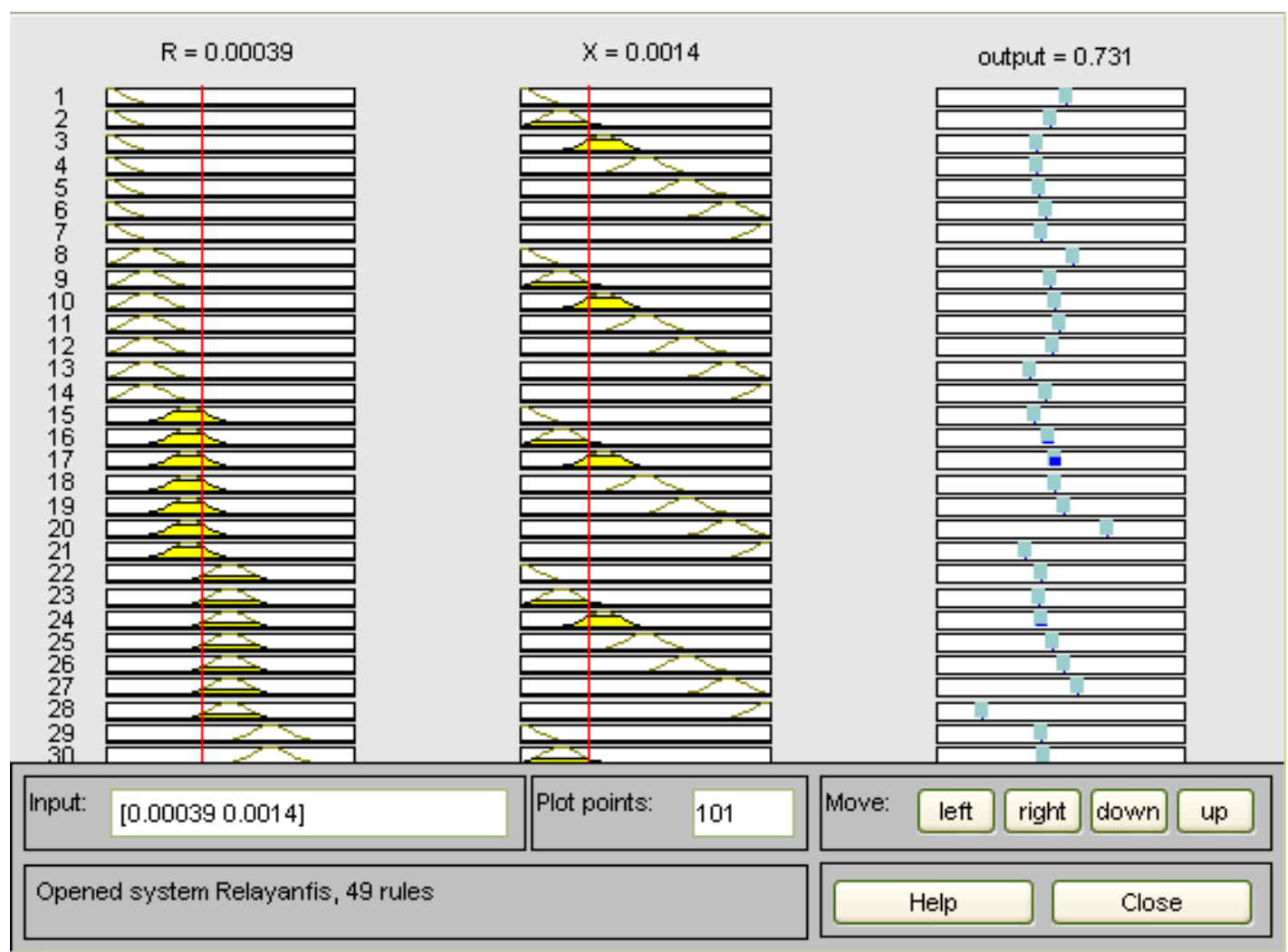

Figure (15) Test results of membership function \& Sugeno corresponding response. 
AL-Kababje: Real Time Based Fuzzy Logic Distance Protection
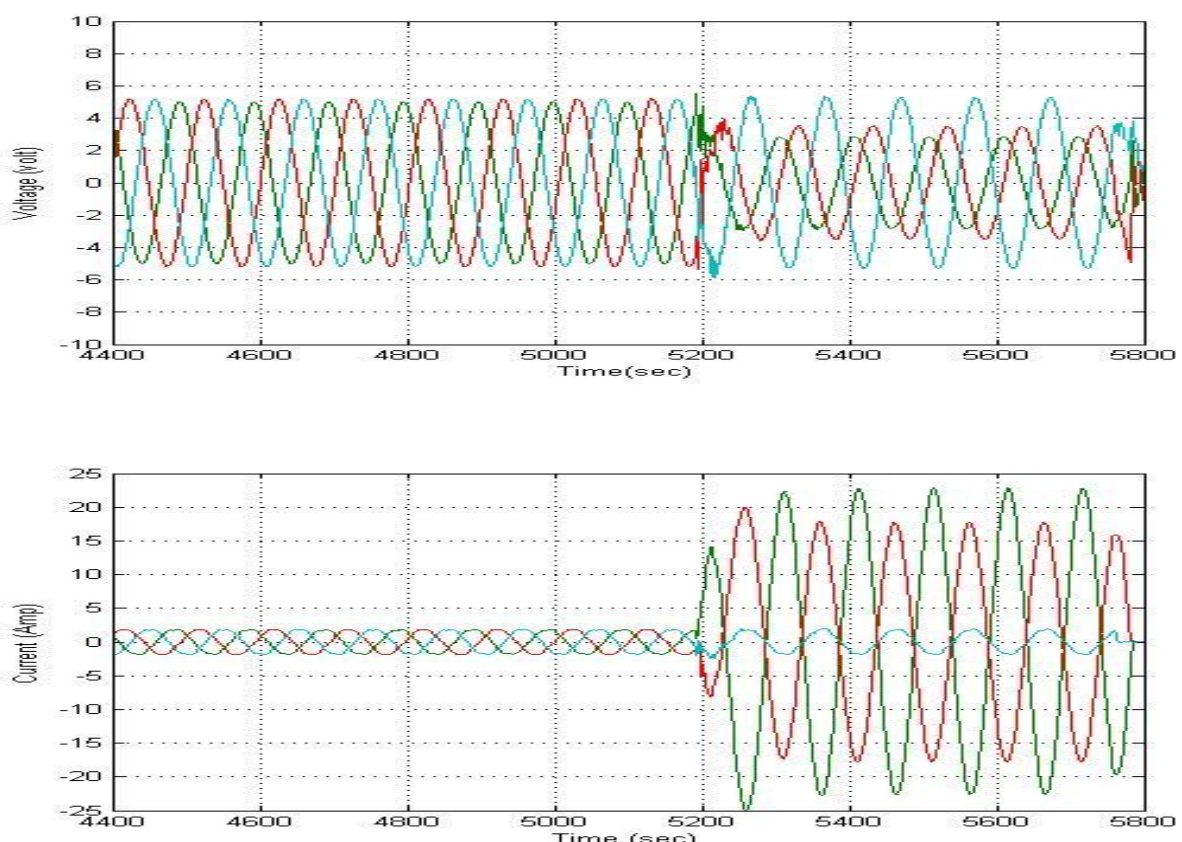

Figure (16) voltage and current signals for phase $a$ and $b$ to ground fault at $100 \mathrm{~km}$

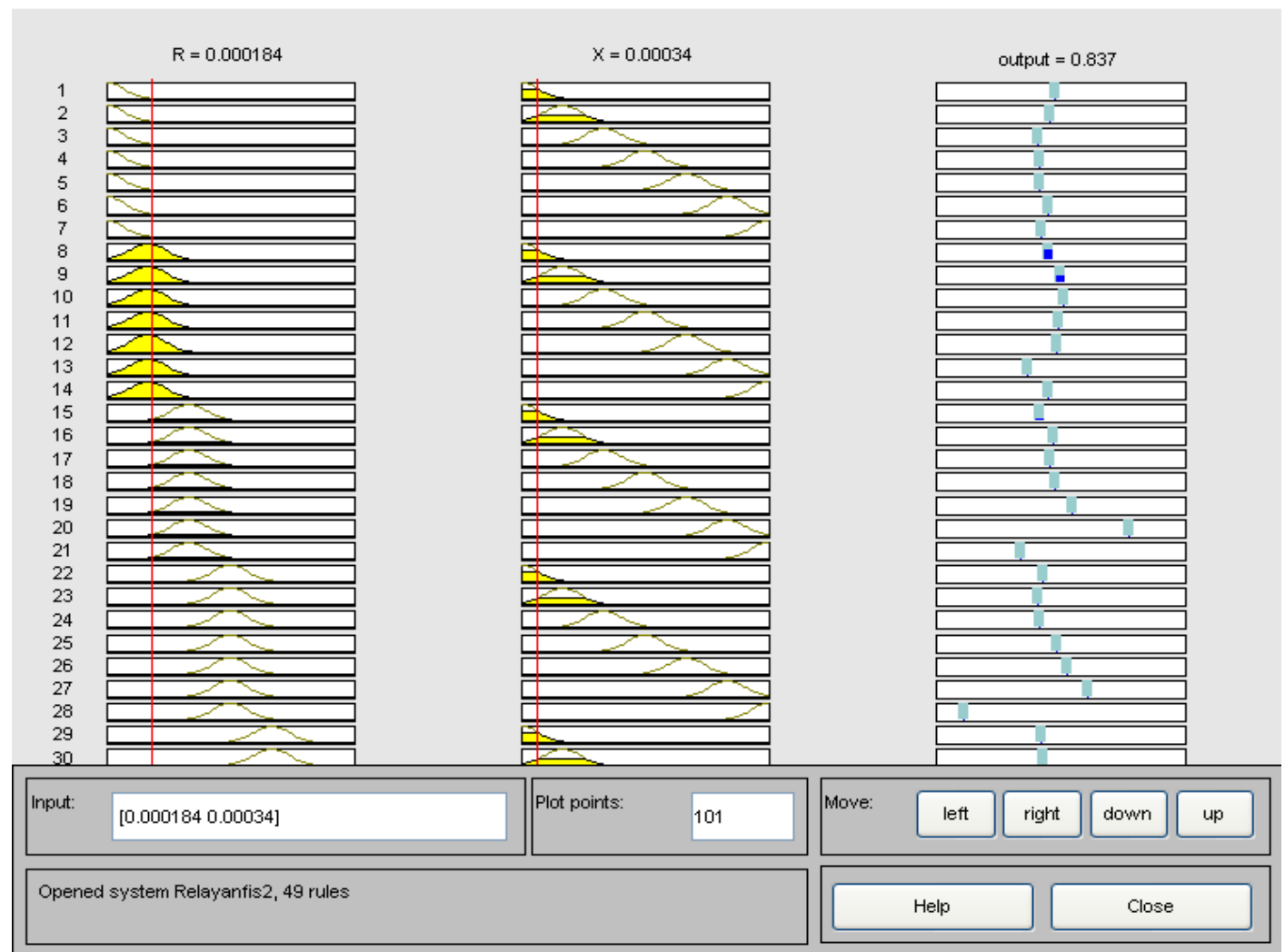

Figure (17) Test results of membership function \& Sugeno corresponding response. 

Al-Rafidain Engineering
Vol.20
No. 3
June 2012

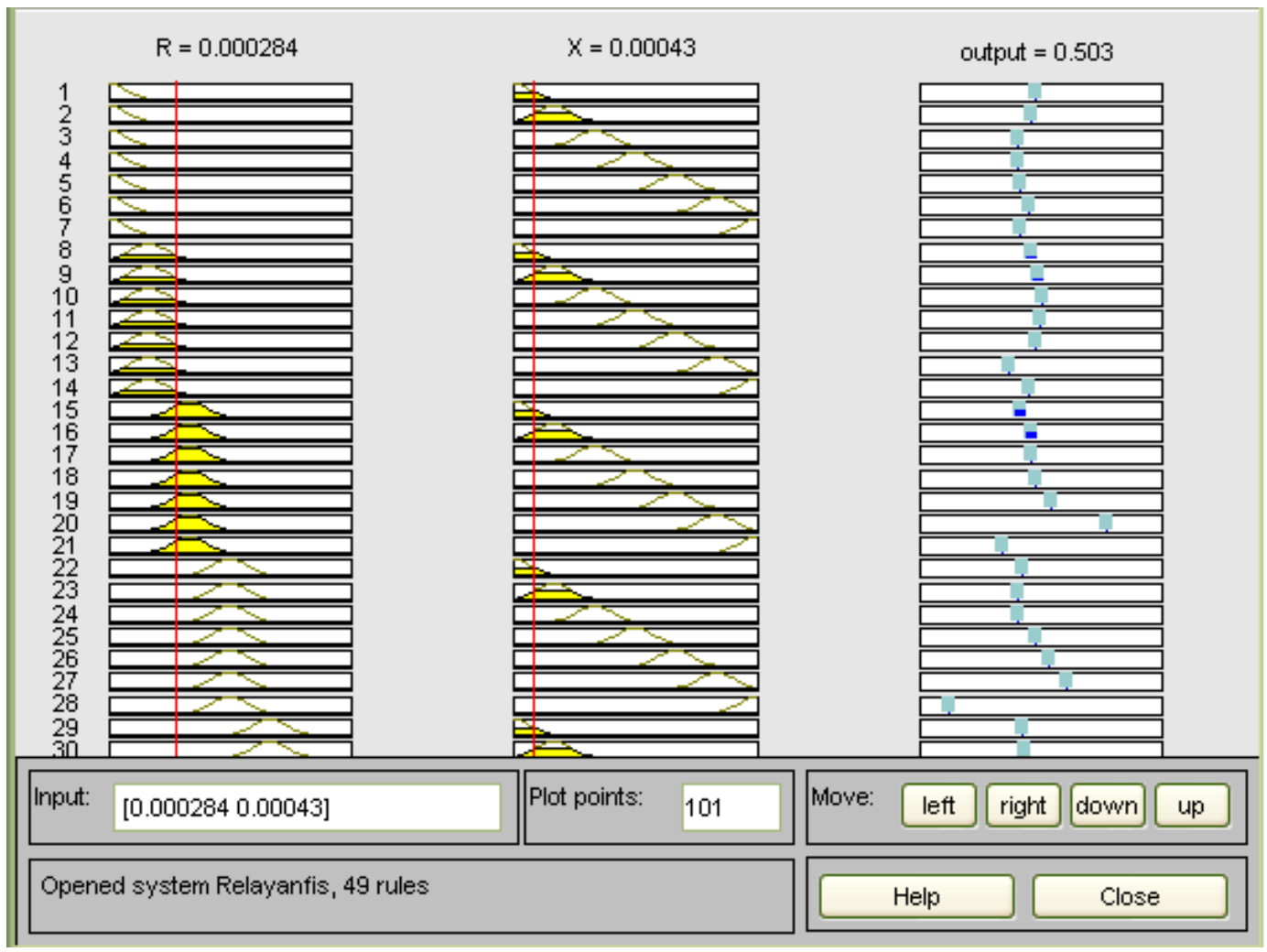

Figure (18) Test results of membership function \& Sugeno corresponding response.

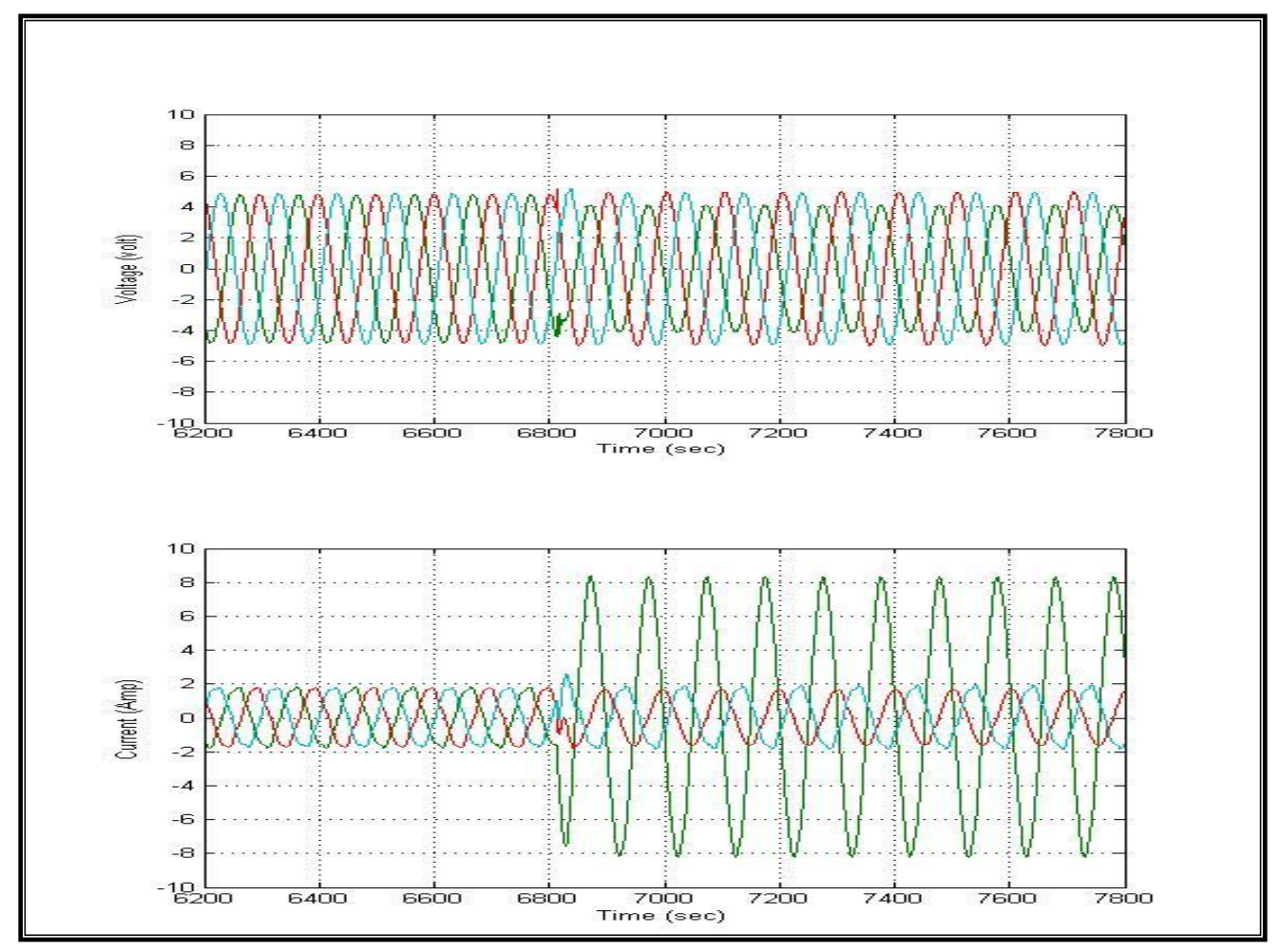

Figure (19) voltage and current signals for phase a to ground fault at $200 \mathrm{~km}$ 
AL-Kababje: Real Time Based Fuzzy Logic Distance Protection

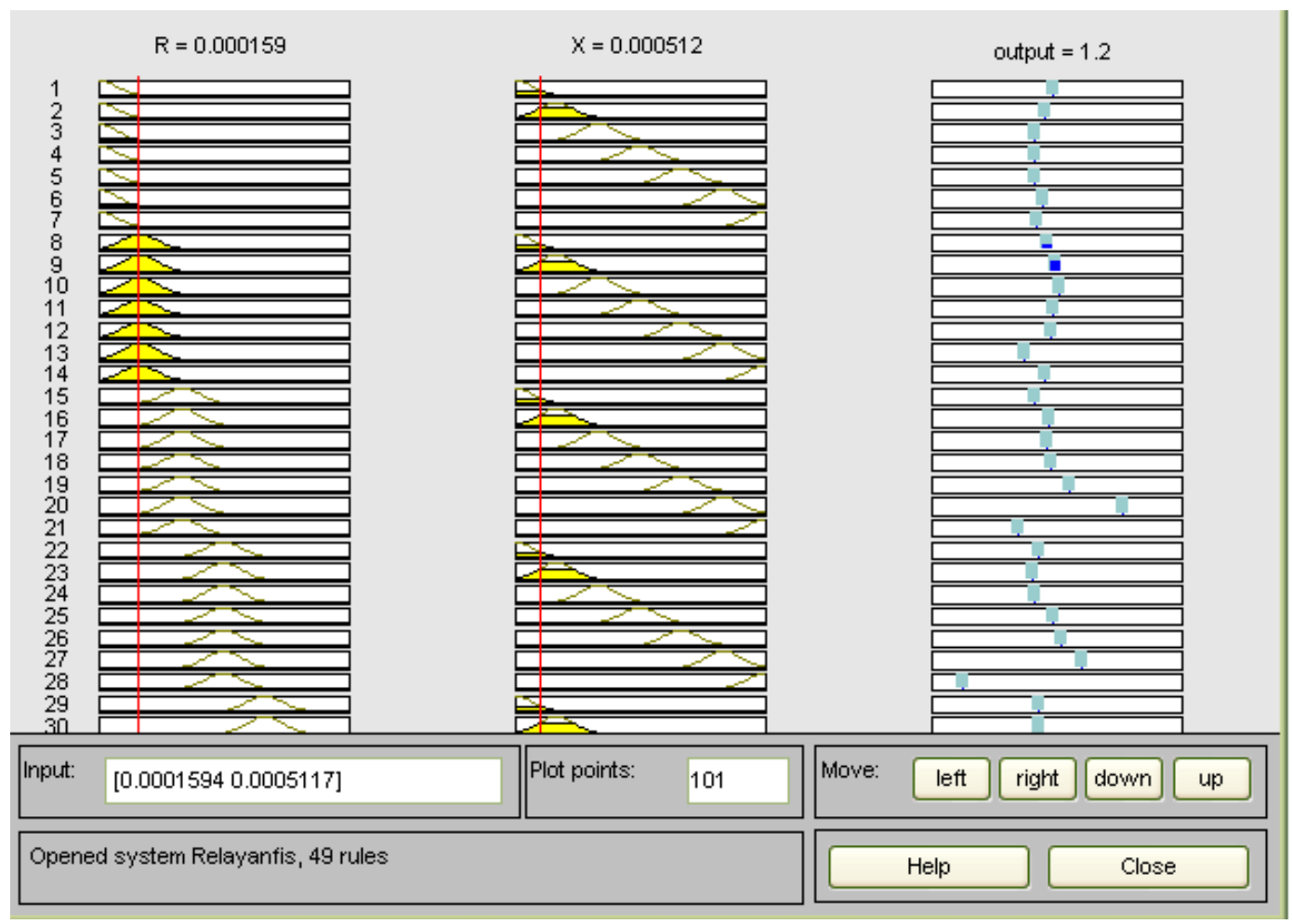

Figure (20) Test results of membership function \& Sugeno corresponding response.

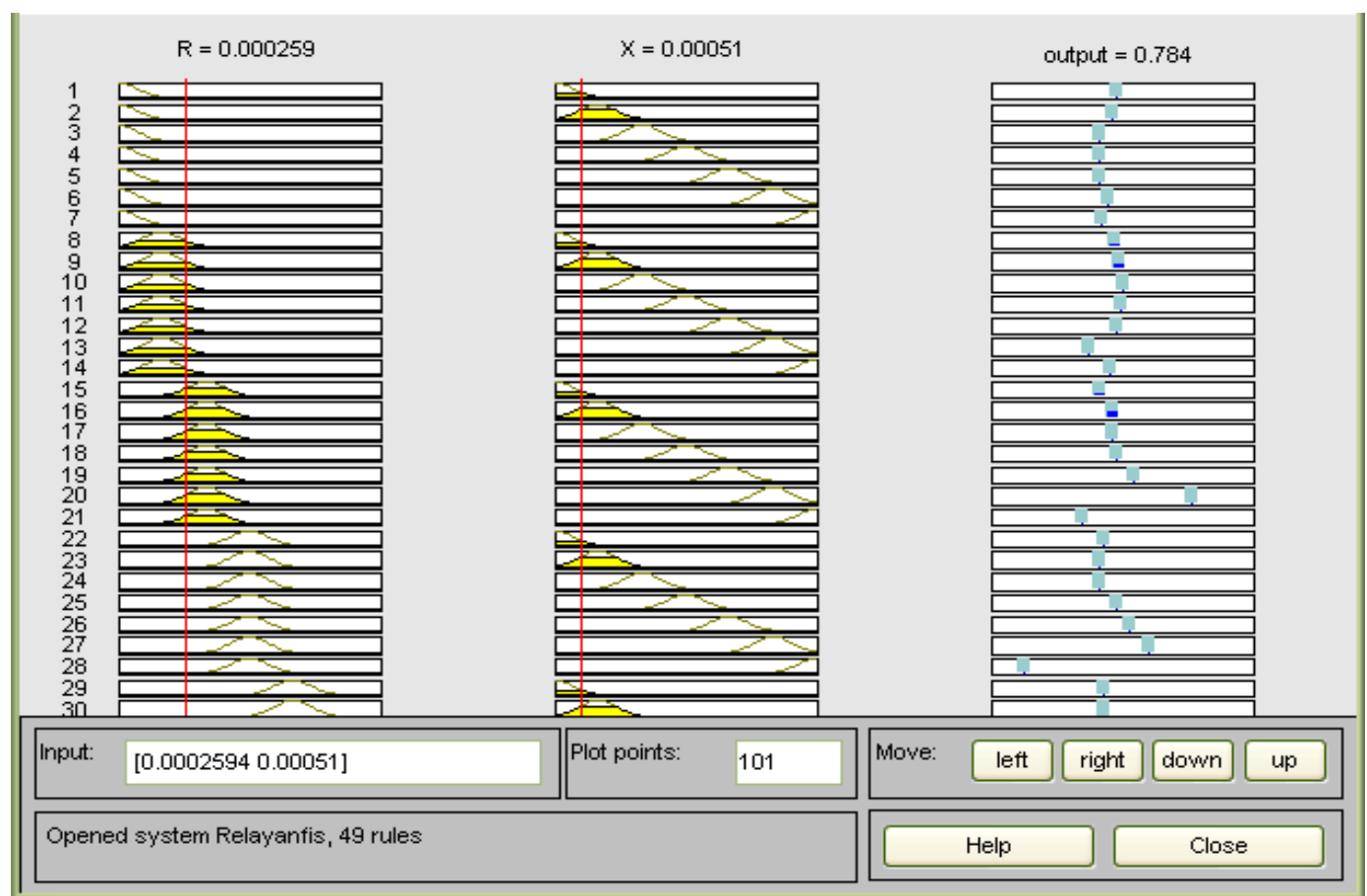

Figure (21) Test results of membership function \& Sugeno corresponding response. 


\section{CONCLUSIONS}

Detection of transmission system faults, using distance relay, with fuzzy logic technique has been achieved in this work. It is proven to be a fast, accurate and robust approach that would perform accurately for various system conditions. Further. the results of real-time implementation is encouraging. This means that the fuzzy model with further refinement can be implemented in an actual power system to monitor occurrence of faults and to take necessary action. The correct detection is achieved in less than $10 \mathrm{~ms}$.

\section{REFRENCES}

[1] M. Sanaye-Pasand , H . Khorashadi-Zadeh "An extended ANN-based high speed accurate distance protection algorithm", Electrical Power and Energy Systems 25,Januray ,2006.

[2] W. W. L. Keerthipala, Huisheng Wang, Chan Tat Wai "On-Line Testing of a FuzzyNleuro based Protective Relay using a Real-Time Digital Simulator", IEEE, Journal: Power Engineering Society Winter Meeting, vol .3,2000.

[3] Hassan Khorashadi-Zadeh , Zuyi Li "Transmission Line Distance Protection Using ANFIS and Positive Sequence Components" Revitalizing Operational Reliability August 1924, 2007, IEEE, USA .

[4] Il-Dong Kim, Raj K. Aggarwal "A study on the on-line measurement of transmission line impedances for improved relaying protection" Electrical Power and Energy Systems 13,December ,2005.

[5] Biswarup Das, J. Vittal Reddy "Fuzzy-Logic-Based Fault Classification Scheme for Digital Distance Protection" IEEE TRANSACTIONS ON POWER DELIVERY, VOL. 20, NO. 2, APRIL 2005.

Appendix (A)

The power station simulated rating and parameters are :

Power $=160 \mathrm{MVA}, \mathrm{f}=50 \mathrm{~Hz}$, voltage $=220 \mathrm{kv}$, current $=422 \mathrm{~A}$, and impedance $=303$.

The transmission line $(100 \mathrm{~km}$ TL) rating and parameters are :

Voltage $220 \mathrm{kv}, \mathrm{f}=50 \mathrm{~Hz}, \mathrm{R}=7 \mathrm{e}-6 \Omega / \mathrm{km}, \mathrm{X}=0.03 \mathrm{e}-3 \Omega / \mathrm{km}$ and $\mathrm{c}=60 \mathrm{e}-3 \mathrm{nf} / \mathrm{km}$.

The work was carried out at the college of Engineering. University of Mosul 